\title{
Qualitative-characterizing complicators in the semantic-syntaxic structure positive copyrinting texts
}

\author{
Irina Zubkova ${ }^{1 *}$, Lidia Alahverdieva ${ }^{1}$, Irina Zhivotkova ${ }^{1}$, and Svetlana Kruglova ${ }^{1}$ \\ ${ }^{1}$ Don State Technical University, Gagarina str, 1a, Rostov-on-Don, 344000, Russia
}

\begin{abstract}
The article concerns with the characteristic features of functioning of qualitatively defining "positive" adverbs-compilers in copywriting texts, which lead to a complication of semantic-syntactic structure and pragmatic content of advertising content and are expressed as the form of free distributors of sentences - determinants that serve as expressive-emotional means of author's intention. It has been determined that "attractive" qualitatively characterizing adverbs are generally considered integral component of the advertising text, which largely forms its stylistic originality. The use of original expressive techniques and various linguistic means by copywriters helps to create a "positive", figurative text, build content according to a certain structure and to form the main idea. Reference to new material, which was not the subject of special analysis, in our opinion, will allow us to obtain additional arguments in favour of qualifying qualitatively-characterizing compilators in the semantic-syntactic structure of positive copywriting texts as determinant members of a sentence.
\end{abstract}

\section{Introduction}

The relevance of this study lies in the need for a theoretical understanding of the issues related to the further development of the doctrine of qualitatively-characterizing complementors in the semantic-syntactic structure of positive copywriting texts and the disclosure of their role as pictorial and expressive means based on the space of determination.

Studies showed that:

1. Qualitatively-characterizing complicators act as freely connected distributors of the entire predicative centre - determinants, that is, they are complex in nature, differ in formal and semantic autonomy, which allows them to act as an integral component of the communicative unit of advertising content.

2. Prepositional-case forms, adverbial and adverbial constructions with a qualitatively characterizing meaning as inherent distributors are a means of an additional semantic centre of an advertising utterance, complicated at the formal and semantic levels.

\footnotetext{
* Corresponding author: irinazubkova164@gmail.com
} 
3. The lexical content and syntactic structure of the copywriting text depend on the author's intentions, communicative-pragmatic context and orient the addressee to the emotional state of the subject. Qualitatively-characterizing complicators are the communicative centre of an advertising statement, most often acting as a kind of semantic and structural organizer of a text fragment, and express an additional emotional-expressive, pictorial-expressive characteristic of advertising content. The pragmatic function of adverbial components is associated with the desire of the copywriter to arrange the word forms of the utterance in such a way that the perception comes either from the known (theme) or unknown (rema) or is accompanied by expression, the speaker's tendency to focus the attention of the addressee on the evaluative potential of the studied units.

Adverbial lexemes, spreading complicating predicative foundations with propositive semantics, enter into a one-sided relationship with the statement, established by "semantic tasks of the context, and not the semantics of any word in itself," grammatically depend on the entire structural and semantic centre as a whole [1]. Depending on these tasks, the quality characteristics complementors are investigated as forms of words that are mandatory "exclusively for a given context, and not for the completeness of the content of the utterance as a whole," or the adverbs under consideration are considered dependent syntactically [2].

The objective of the current study was a comprehensive description of the structuralsemantic and communicative-pragmatic potential and aesthetic function of utterances with "positive" qualitatively-characterizing compilers as pictorial and expressive means in copywriting texts.

\section{Materials and methods}

The material for this research was copywriting texts published on the Internet and periodicals intended for a wide range of readers.

The purpose and objectives of the work determined the use of various research methods: functional analysis of linguistic material, descriptive-analytical, structural-semantic, transformational methods, as well as elements of statistical calculation. The analysis was carried out in a comprehensive manner, using at each stage of the work those methods and techniques that correspond to the set goals and objectives of the study.

\section{Results}

The work for the first time describes in the structural-semantic and communicativepragmatic aspects, statements with qualitatively-characterizing compilers in copywriting texts; gives a systemic classification of the investigated adverbial components from the point of view of morphological and syntactic expression, obligatory / optional constructions; investigates the textual and semantic potential of adverbial units as pictorial and expressive means in advertising content. The statement on the expressive function of adverbial complicators, acting as a significant linguistic component of the advertising text, a "powerful weapon" of copywriting, is affirmed and substantiated. Thus, the results of the behavioral study broaden the understanding of the participation of determinant word forms with a qualitatively characterizing meaning in the formation of additional meanings based on the implementation of the author's intentions, as well as the pragmatic and communicative influence of the compilers on the consumer's choice by creating a special emotional-positive effect. 


\section{Discussion}

Freely attachable structures are the background of the picture and can indicate, for example, a place or time. This function of the minor members of T.I. Antonova calls it "framework". P. Adamets also expresses a similar point of view. So, to the group of adverbs, he refers only to those members that are semantically and syntactically autonomous, do not follow from the valency of the verb, circumstances have a meaning and, as it were, are "backstage" for other members of the sentence. We believe that the comparison of these minor members with the "curtain", "frame" leads to the fact that in the studied syntaxemes we observe something similar to an auxiliary means, and not to a structural component of a common / complicated sentence. In addition, to characterize adverbial lexemes as "background", "frame" of an expression means, in essence, to take them beyond the boundaries of the utterance [3].

In the understanding of S. King, adverbs were invented for a humble author and it is worth using them exclusively in rare cases, that is, they cannot be "our friends". So, using adverbs, the writer is afraid of inaccurate, inaccurate explanation of the meaning of any statement, the listener's misunderstanding of the author's position or artistic reflection of reality [4]. This assumption is reflected by S. King in the following example:

- Put! She shouted.

- Give it back, - he begged, - it's mine!

"Don't be such a fool, Jekyll," Utterson said [ibid.].

Further, in the dialogue containing verbs of speech-thinking activity (shouted, prayed, said), the writer includes qualitative-semantic adverbs. Let's compare the transformation text:

- Put! She shouted ominously.

- Give it back, - he humbly pleaded, - it's mine!

"Don't be such a fool, Jekyll," Utterson said contemptuously.

In these works, the authors don't agree with the opinion of S. King that such dialogical statements-transformations refer to "actively ridiculous cliches". We believe that the qualitatively characterizing adverbs-complators are a powerful speech tool, focusing the recipient's attention on certain properties and details of expression, as well as making the speech brighter, more beautiful, more emotional, and richer.

Confirming our thought, let's analyse the article from the Explanatory Dictionary of the Russian Language by S.I. Ozhegova, N.Y. Shvedova. Look at the lexical meaning of the word "scream": 1. Make a scream. K. from pain. 2. Talking too loudly. Don't shout, speak calmly. 3. To whom (what). Scold someone, speak harshly with someone. K. on the mischievous person. 4. About someone. To discuss a lot and in detail about something. topical (colloquial). Newspapers shout about a sensation. Based on the lexical and grammatical information presented in the dictionary entry, we come to the conclusion that the specific meaning of the verb "shout" used in the expression is "Put it down! - she shouted, "it becomes not entirely clear." Consequently, not only the author's intention suffers, but also the communicative-pragmatic aspect of expression and the semantic load of the structure are not sufficiently expressed. The adverb "ominous" in the sentence - "Put it down! - she shouted ominously "performs not only an informing function, but also an influencing, emotional-evaluative one, noticeably increases the subjective content of the utterance, realizes a single speech. Consequently, without qualitatively characterizing adverbs-complementary, the accuracy of the author's intentions, characteristics, emotionalexpressive colouring, picturesque utterance would be lost. Thanks to adverbial word forms, the most important, necessary element of the phrase as a whole is emphasized, its stylistic originality is formed. 
Free attachment, which is a way of formalizing subordinate links in a sentence, firstly, demonstrates a one-sided dependence, the tendency of the adverbial syntaxeme to extend, explaining something to a text element; secondly, this connection shows that the use and design of the adverbial construction are not in any way conditioned by the qualities of the supplemented content and these syntactic turns, as a rule, do not depend on the environment of semantics, they can be easily rearranged in another place or "omitted", removed completely in within one expression without any significant semantic change. The following examples of advertising and informational content can be cited as illustrative material:

1. Our company "ProfilStalGroup" produces various sandwich panels, and also delivers and assembles them throughout Russia. In the building materials market, we have established ourselves as a responsible, respected and conscientious partner. Prices for our sandwich panels differ from competitors in their advantageous side. The use of sandwich panels in construction makes it possible to mount a variety of structures economically, quickly and, practically without paying attention to the weather. It is very profitable to purchase sandwich panels from the manufacturer directly.

2. "To make it easier for you to plan your daily affairs, our application is perfect for you."

The communicative and pragmatic feature of the considered advertisements is considered their special "attractiveness", formed by the use of specialized "attractive" adverbs-compilers by copywriters: "economical", "fast", "very profitable", "ideal". We believe that these circumstantial elements have a certain psychological effect on the recipient and significantly contribute to an increase in the effectiveness of advertising content, the lexical meaning and syntax structure of it depend on the creative sense of the copywriter, the context and the circumstances of communication. In the informational texts we have taken as an example, the compilers with a qualitatively characterizing meaning carry a huge connotational semantic load: to a large extent, these adverbs turn out to be leading in terms of expressing not syntactic structure, but semantics, while the advertising message is informative, concise, dynamic and emotionally -expressive [5].

After the recipient gets acquainted with such attractive and convincing advertising content, the addressee forms a pleasant "aftertaste": positivity, trust, honesty, "warmth and liveliness of words." With their peculiar statements, copywriters seem to inform the consumer: "We are the best, we will not let you down", show all kinds of advantages without clichés, cliches and pathos. From this view of the communicative goal in the advertising content, the position of the considered qualitative compilers in the topic and rem is strictly specialized and is largely according to the fact that the functioning of these word forms goes beyond the framework of a specific statement, which allows the adverbial unit to act as a structural and semantic bond - the organizer of the text fragment. The copywriter tries to arrange the components of the advertising utterance in such a way that their perception goes sequentially from the known to the unknown or is accompanied by expression, dynamism, the addressee's tendency to focus the recipient's attention on the evaluative, positive, "attractive" potential of qualitatively characterizing circumstances. That is the result of the copywriter's communicative intentions.

An effective means of pragmatic influence on the state of the recipient is the use of quality semantics in copywriting texts, since it is these linguistic units that are, in our opinion, the main method of creating the expressiveness of advertising content, contain additional semantic and stylistic evaluative connotations, emphasize information on important parts of the statement, stand out in parceled structures, giving them a great semantic and emotional load. Taking the position of adverbial determinants, they turn out to be the only members of the sentence outside the predicative group, not extending any of its components separately. 
Let's correlate the advertising text-parcels and its transform-construction:

1. Myths about business. "Free schedule. No alarms. No bosses. No Mondays! " = There are various myths about business when you are offered a free schedule. You don't have to wake up at a particular time. You don't have to report your boss about each step. You don't have to go to work on the hardest day of the week - Monday!

2. Your electrician. I work personally. Without intermediaries. High quality and fast!

The removal of high-quality word forms outside the limits of the utterance makes it possible to actualize, emphasize the characteristic that determines it, to give special significance to the expression. Naturally, the dismemberment of syntactic constructions is closely associated with their lexical content, but in terms of content it is richer, more emotional, more informative in relation to the full version. In this case, the excretory communicative-pragmatic function of parcelling is combined with the propagatingcomplicating one. The purpose of such parceling is to facilitate the perception of the statement, to enhance the expressiveness of the advertising text, to give it special expressiveness and evaluativeness. It should also be noted that the parceled word order, determining the meaning of the utterance, simultaneously performs a syntactic function (expresses the syntactic organization of the structural and semantic core of the utterance), communicative (is a means of actual division of the utterance) and stylistic (serves as an expression of the expressive qualities of speech). Thus, the qualitatively characterizing complement in advertising content functions as a pragmatically significant syntaxeme, denoting a pragmatic peak, given, opposed to the entire predicative group as a whole (new).

A special psychological colouring and at the same time a certain difficulty to modern texts of "positive" copywriting is given by stable turns with a qualitatively characterizing meaning, where they are a vivid means of creating imagery. It concernce with the fact that the phraseological phrase often appears in the advertising content in a transformed form, since for copywriters it is one of the types of language game. For example:

1. Over the years I have learned a dozen little tricks and it makes my life a little better. Well, in total they turned out to be able to make my life much better - not even "a little". But those things that turned out to be able to change my life for real were the result of several insights that turned my world upside down and forever changed my reality.

2. She wanted to live in Manhattan, but the truth is she could afford only a closet.

3. Science goes with tall steps - humanity is no longer keeping up with it.

Qualitatively-characterizing complicators, expressed in phraseological phrases: "who turned my world upside down", "affordable", "strides forward by leaps and bounds", have a certain connection with various linguistic parts, and as a result are already "pragmatically charged" by themselves, which makes it possible for the copywriter to make the texts attract the attention of the addressee, catchy, memorable, "awaken" the recipient's interest in the object of advertising.

Let's look at the fact that in information content, paremias and fixed phrases often undergo a kind of processing, in other words, copywriters use various occasional varieties of the studied syntax units in order to expressiveness of advertising. So, a phraseological expression is taken in part, that is, a general image or content is used, a certain rhythmicsyntactic organization is played out. Consider the transformation phraseological unit in the following example:

Together we will move mountains! ... "If someone has nothing to do, let him seek! After he finds it" I mean, that mess is with success. I mean, get two birds in your hand in the form of profit copywriting from White PR!

In the presented advertising content, we observe the persistent expression "get a crane in your hand", which has undergone a noticeable deformation (compare: better a tit in the hand than a crane in the sky ...), or "together we will move mountains" (compare: together we will move mountains). Note that these phraseological turns can cause a variety of 
associations, certain feelings and emotions in the recipient, and influence the processes of perception. The value of phraseological units in an advertising text is that they are familiar and recognizable, which means that the consumer's ability to perceive, remember and reproduce a slogan containing a familiar phrase increases dramatically. Thus, the use of steady turnovers in advertising is both an effective and very effective means of influence. Intriguing the consumer, phraseological units emotionalize the perception of advertising information, forcing the addressee's imagination to work and generating an associative array associated not only with the promoted product itself, but also with the cultural context in which its advertising is embedded.

To make the text "lively", "juicy" the copywriter helps a metaphor - a trope that can be safely called a unique phenomenon involved in linguistic creation; a means used to make speech more expressive and colourful. What is the fantastic success of this means of speech expression? The fact that it emotionally and figuratively affects not only the mind, but also the feelings and, in the end, makes a person make up the opinion the author needs. In short, the metaphor is a real treasure for the pen and keyboard worker who longs to impress the minds of his readers. A metaphorical assessment is known to every person, including those who know nothing at all about the advertised product and its properties. Moreover, the metaphor is capable of being interpreted by the addressee to such an extent that in the final result the recipient appears as a co-author of the advertising image.

Gary Bensinweng, a famous copywriter, explained the effectiveness of this trope as follows: correctly formed metaphors magically transform the minds of listeners, since the transfer of qualitative characteristics from one subject to another is carried out with lightning speed, while there is no resistance or critical analysis. All that remains is to compare A and B ... and voila! - you find yourself at the goal without any resistance on your way. A beautiful metaphor is a real magician of persuasive speech! The authors of the article share this opinion. Indeed, a good metaphor helps the listener's mind to freely trust the advertising image, quickly and fairly easily memorize it, has the ability to fascinate the recipient, while evoking the appropriate marketing associations and forming the necessary idea of the brand of the product.

For example:

1. Make-up removal and skin tone ta one scoop! Yves Rocher Hydra Vegetal Hydrating Micellar Water 2 in 1 thoroughly removes makeup and removes impurities; intensively moisturizes the skin; makes the skin soft, shine and bright. Your face and eye are free of make-up, and your skin is shine and moisture!

2. Puzzling over what to give your mother-in-law for the anniversary? Are you afraid to make a depressing impression on her and make big trouble? Give her a tour of Jurassic Park! This unforgettable journey guarantees your second mom a lot of vivid impressions that she desperately needs. She will love the intimate atmosphere of the park, and you will receive warm words of gratitude.

Such advertising content is metaphorical and, as it were, call on the recipient to see the world through the game reality, influencing the addressee with a positive influence, tightly "packing" meanings and simultaneously saving the efforts of the advertiser. The essence of the use of metaphors in advertising texts is related to the fact that hidden comparisons affect the specific judgment of the recipient without the presence of evidence, thanks to this path, generally recognized values are presented as ready-made arguments that can hardly be refuted. Qualitatively-characterizing compilers play an important role in the communication process, since they not only shape the structure of the statement, but also significantly affect its content, pragmatic side. 


\section{Conclusion}

Consequently, high-quality adverbs-compilers become a significant linguistic component of the advertising text, a "powerful weapon" of "positive" copywriting. The frequency of the use of qualitative-characterizing complementors as means of expression according to the degree of their activity in the semantic-syntaxic structure of positive copyrating texts is presented in the Table 1.

Table 1. The frequency of the use of qualitative-characterizing complementors as means of expression according to the degree of their activity in the semantic-syntaxic structure of positive copyrating texts.

\begin{tabular}{|c|c|}
\hline Expression means & Frequency \\
\hline Phraseological unit & $38 \%$ \\
\hline Metaphoric expression & $34 \%$ \\
\hline Parceling & $10 \%$ \\
\hline Dephraseological unit & $4 \%$ \\
\hline Other expression means & $2 \%$ \\
\hline
\end{tabular}

These adverbial constructions provide a high intensity of pragmatic-communicative influence on the consumer's choice by creating a special emotional-positive effect. The recipient's assessment is the most important relevant component of the pragmatic meaning of speech advertising content, which differ both in the purpose of the statement, thus the sense and level of implementation of the copywriter's communicative intentions, which provides the nature of the expression of the utterance, and the expression of emotions, assessments, hidden meanings, and the impact on the recipient, his thoughts, feelings, desires, needs. The use of specific stylistic techniques and peculiar linguistic means provides an opportunity for copywriters to structure the advertising text, emphasize its main idea, create figurative, "attractive" content marketing in order to get trust and attract potential customers. The compiler with the qualitatively characterizing meaning of the situation functions in the advertising text as an active stimulator of the process, is used as the author's means of creating imagery of content and as a stylistic and expressive means that helps the addressee to most fully present the information intended for his understanding, to identify the communicative intentions of the copywriter, to determine which expression was used. Thus, utterances containing quality compilers have structural flexibility and broad functionality that help the addressee to guide the communication process and to anticipate its results. The use of adverbial distributors in advertising texts is always intentional, associated with the need to accentuate some aspect of meaning and may be caused by certain stylistic needs.

\section{References}

1. O. Akay, A. Kalashnikova, I. Kalashnikov, A. Golubeva, In Proceedings of the 7th International Scientific and Practical Conference "Current issues of linguistics and didactics: The interdisciplinary approach in humanities" (CILDIAH 2017), 97, 9-14 (2017), doi:10.2991/cildiah-17.2017.2

2. I.V. Aleshchanova, E.V. Morozova, N.A. Frolova, M.R. Zheltukhina, In Proceedings of the 7th International Scientific and Practical Conference "Current issues of linguistics and didactics: The interdisciplinary approach in humanities" (CILDIAH 2017), 97, 19-24 (2017), doi:10.2991/cildiah-17.2017.4 
3. N.G. Vartanova, M.S. Volodina, In Proceedings of the IV International Scientific and Practical Conference "Anthropogenic Transformation of Geospace: Nature, Economy, Society", 297-300 (2020), doi:10.2991/aer.k.200202.060

4. M.S. Volodina, N.G. Vartanova, A.P. Prohorova, In European Proceedings of Social and Behaviour Science, 104, 1095-1100 (2020), doi:10.15405/epsbs.2021.02.02.135

5. E. Klemenova, A. Berezin, N. Berezina, et al., Lecture Notes in Networks and Systems, 131, 914-921 (2020), doi:10.1007/978-3-030-47415-7_98

6. N.M. Loktionova, I.A. Kuzminova, I. A. Zhyvotkova, S.A. Kruglova, In Proceedings of the 7th International Scientific and Practical Conference "Current issues of linguistics and didactics: The interdisciplinary approach in humanities" (CILDIAH 2017), 97 (2017), doi:10.2991/cildiah-17.2017.26

7. N.M. Loktionova, I.A. Kuzminova, S.A. Kruglova, In Proceedings of the 7 th International Scientific and Practical Conference "Current issues of linguistics and didactics: The interdisciplinary approach in humanities" (CILDIAH 2017), 50 (2017), doi:10.2991/cildiah-17.2017.26

8. N.M. Loktionova, O.A. Fomina, I.A. Kuzminova, Humanities, Social-Economic and Social Sciences, 5 (2013), doi:10.23683/1995-0640-2018-4-74-81

9. N.M. Loktionova, O.A. Fomina, L.K. Alakhverdieva, Proceedings of the 7 th International Scientific and Practical Conference "Current issues of linguistics and didactics: The interdisciplinary approach in humanities" (CILDIAH 2017), 97 (2017), doi:10.2991/cildiah-17.2017.61

10. I.G. Ovchinnikova, T.V. Akhutina, Language and Thought: Modern Cognitive Linguistics, 3, 131-140 (2016)

11. N.M. Loktionova, S.A. Kruglova, O.A. Drozdova, In Proceedings of the International Scientific and Practical Conference "Current Issues of Linguistics and Didactics: The Interdisciplinary Approach in Humanities and Social Sciences" (CILDIAH-2018), 50 (2018), doi:10.1051/shsconf/20185001019

12. S. Bylkova, D. Shalkov, E3S Web of Conference, 210, 10 (2020), doi: 10.1051/e3sconf/202021018010

13. A.A. Kalashnikova, O.M. Akay, I.V. Tsarevskaya, M.S. Volodina, E.O. Tsybenko, Man in India, 19, 161-172 (2018)

14. S. Jacobson, J Marino, R. Gutsche, Journalism, 17(4), 527-546 (2015), DOI: doi:10.1177/1464884914568079

15. S.V. Bylkova, E.P. Chubova, Innovative Technologies in Science and Education (ITSE 2020), 210, 10 (2020), doi:10.1051/e3sconf/202021022006

16. S. A. Chunikhin, et al., Entrepreneurship and Sustainability Issues, 6(4), 1663-1679 (2019), doi:10.9770/jesi.2019.6.4(8)

17. C. Wolf, A. Godulla, Journal of Media Business Studies, 13, 199-221 (2016), doi:10.1080/16522354.2016.1184922

18. M.Ch. Kremshokalova, Izvestija Russian State Pedagogical University im. A.I. Herzena, 151, 89-96 (2012)

19. T.J. Sazonova, I.S. Borozdina, Voprosy Kognitivnoj Lingvistiki, 2(023), 27-33 (2010)

20. E.G. Beyninson, Scientific Bulletin of YIM, Linguistics and communication problems, 4, 37-39 (2014) 